\title{
Acceptors of Population Programme in Pakistan
}

\author{
SABIHA HASAN SYED*
}

\begin{abstract}
Data from Pakistan's population planning programme, the National Impact Survey (1968) and the Pakistan Fertility Survey (1975) are analysed to estimate the number of 'births averted' in Pakistan by various contraceptives. Limitations of the population planning programme statistics for determining the impact of the programme on fertility rates are pointed out.
\end{abstract}

\section{INTRODUCTION}

The present paper is an attempt to analyze the information available from the programme statistics of Pakistan's Population Planning Programme along with other relevant data from the National Impact Survey (1968) and Pakistan Fertility Survey (1975) in order to examine estimates of births averted in Pakistan by the various contraceptives supplied through the Population Planning Programme.

In this analysis we shall correlate the available information ${ }^{1}$ on contraceptive supplies with their use in Pakistan, and examine the relationship between programme statistics and the demographic data collected through sample surveys. It is hoped that this analysis, by providing an overall assessment, will suggest better ways to measure the effect of contraceptive supplies on fertility.

In Pakistan's Population Planning Programme - earlier called Family Planning Programme -, statistical reporting on the programme performance has been an integral part of the programme since 1965 , when family planning services were expanded for nationwide coverage. Monthly acceptor targets were set to ensure that work was continuous throughout the year. From 1970 onwards, "home-visit" targets, based on area population, were set for the field staff. The performance of the Programme since 1965 is shown in Table 1. The distribution of oral pills shows a continuous rise after 1970-71, when distribution without a prescription was authorized in the national Family Planning Programme.

*The author is Director General (Programme), Women's Division, Government of Pakistan, Islamabad. She wishes to thank the anonymous reviewers and referees of this Review for their helpful comments and suggestions on an earlier draft of this paper. She is also very grateful to S. H. H. Naqavi for his valuable editorial help.

${ }^{1}$ The Population (formerly, Family) Planning Programme statistics provide a record of its activities by the programme apparatus itself. 


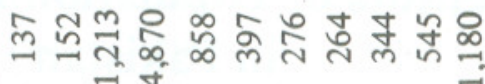

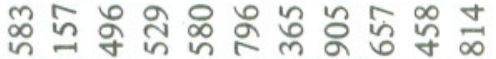

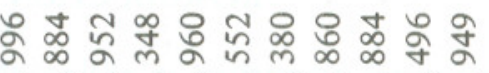

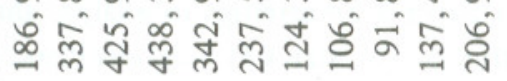

The procedure most consistently and commonly used since 1965 has been to convert acceptance figures into 'Couple-years of protection' (CYPs), i.e. the length of time for which couples are removed from the risk of child-bearing by contraceptives distributed in the programme [4]. Based on current birth intervals, these couple-years of protection are considered equivalent to a certain number of avoided births ("averted birth" in current terminology) ${ }^{2}$, the exact number depending on the particular type of contraceptives used, since different contraceptives yield different ratios between the CYPs and the number of births averted.

After January 1972, the concept of CYP was modified with the addition of the new concept of "Notional Acceptors" (NAs). A notional acceptor approximates one couple-month of protection, representing the number of "continuous users" at any point in time. The NAs lead to a certain number of CYPs which, in turn, are used to estimate the births averted [2]. The present assumptions for estimating CYPs are different from the one used by Bean and Seltzer [1] in the programme prior to 1971.

The present practice of estimating the births averted has been explained by Pakistan's Planning Commission as follows:

The only possible way of converting the operational output into births averted is by using the conversion co-efficient based on assumptions. The assumptions are reasonable
as far as sterilizations and IUDs are concerned but look to be false for conventional as far as sterilizations and IUDs are concerned but look to be false for conventional contraceptives which form by and large a major component of a programme. No studies are available on the sexual behaviour of our population as to how many conventional
contraceptives are required to give one month's protection for conversion into notional acceptors. [7, p. 201]

Another category frequently used in programme statistics is that of "eligible couples" or "target population", i.e. those couples whose women are of child-bearing age (15 - 49 years). According to the Sialkot District experience [6], on which the Continuous Motivation System (CMS) is based, there are about 130 eligible couples per 1,000 population, meaning that in the whole population there are roughly 8.8 million eligible couples to be reached at any time[2]. While this approximation itself is questionable, the potential for inaccuracy is compounded when it comes to the estimate of notional acceptors among these couples. The listing of notional acceptors only indicates the number of certain units of contraceptives sold to couples, not the actual use of those contraceptives.

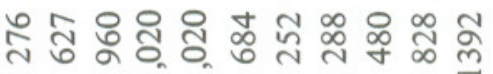

${ }^{2}$ We do not know whether the couple would have had a birth otherwise, or whether a birth has been postponed and will be caused, intentionally or accidentally, later. In what follows we assume that couples resume normal pregnancy risks, as opposed to higher or lower risks, when they leave the programme. 


\section{METHODOLOGY}

We have calculated current use from the family planning programme's statistics that are used as the basic information about the programme's performance with respect to supplies and services for the various contraceptives provided through the programme up to the time that the Pakistan Fertility Survey was conducted. The programme makes very simple assumptions for converting supply figures to use figures. In the absence of data on the continuation rate of the various contraceptives, we have estimated the current users and the births averted by a method based on new assumptions for wastage in the case of conventional contraceptives and oral pills. For estimating the "current use" of IUDs and sterilizations, we have used the following simple formulas to determine the retention rate and survival rate.

IUDs

To help compare the reported use of the IUDs, as given in the programme statistics, with the active use, we give in Table 2 the number of active IUD users at the time of the Pakistan Fertility Survey (1975), as computed by the following formula:

$$
\mathrm{Y}=\mathrm{ae}^{-\mathrm{rt}}
$$

where

$\mathrm{Y}$ is the retention rate at time $\mathrm{t}$,

a is the constant $(=.8444$ here $)$ that allows for immediate expulsion, and

$r$ is a constant $(=.0346$ here $)$ that measures the monthly rate of discontinuation.

In Table 2, current users are shown at time $t=\mathrm{ae}^{-\mathrm{rt}}$, where the constants a and $\mathrm{r}$ were found from continuation rates for Pakistan in 1968. No users were carried beyond the fifth year after their acceptance. Since the regression was based on only two years' experience, the curve could not be extrapolated indefinitely. The factor $r$ also incorporates female survival rates. The estimates of current users and births averted are shown in Tables 2 and 3.

\section{Sterilization}

Current acceptors of sterilization were estimated on the assumption that everyone conitinues from the time of acceptance to the death or separation of either spouse. A correction for mortality of one spouse is made to allow for the aging out of the fertile age range. All couples were considered to terminate after eight years, which is to say that we leave them out of the current-user estimates after that time. Sterilization studies have shown that the allowance of 7.5 years of protection may be sufficient, since the average age of vasectomy acceptors is 45.6 years [12], which indicates that their wives have had more than six children and are either menopausa or nearing menopause. In Table 4 , Column 3 , in order to estimate the number of births averted by sterilization, we have distributed the births evenly over a seven year period, beginning 18 months from acceptance, which puts them in the mid point of the calendar years. (The mean date of acceptance is taken as January 1 , since in Pakistan the statistical year begins on July 1. The 18-month delay thus moves events to the middle of the calendar years.)

Table 2

Estimated Total IUD Users as of August 1975

\begin{tabular}{|c|c|c|c|c|c|}
\hline $\begin{array}{c}\text { Year of } \\
\text { Acceptance } \\
\text { (July-June) }\end{array}$ & $\begin{array}{c}\text { No. of } \\
\text { Acceptors }\end{array}$ & $\begin{array}{l}\text { Time }^{\mathrm{a}} \text { (in } \\
\text { month) Elap- } \\
\text { sed to in } \\
\text { P.F.S. }\end{array}$ & $\begin{array}{l}\text { Continua- } \\
\text { tion } \\
\text { Rate }^{\mathrm{b}}\end{array}$ & $\begin{array}{c}\text { Sur- } \\
\text { vival } \\
\text { Rate }^{c}\end{array}$ & $\begin{array}{l}\text { Current } \\
\text { Users } \\
\text { Col. } 2 \times \\
4 \times 5\end{array}$ \\
\hline (1) & (2) & (3) & (4) & (5) & (6) \\
\hline $1971-72$ & 124,380 & 44 Months & .1844 & .9854 & 22,601 \\
\hline $1972-73$ & 106,860 & 32 Months & .2792 & .9894 & 29,518 \\
\hline $1973-74$ & 91,884 & 20 Months & .4228 & .9933 & 37,594 \\
\hline $1974-75$ & 137,496 & 8 Months & .6403 & .9973 & 87,804 \\
\hline $\begin{array}{l}1975 \text { (July - } \\
\text { Dec.) }\end{array}$ & 112,884 & $\begin{array}{l}1 \text { Month, } \\
7 \text { days }\end{array}$ & .7948 & .9994 & 89,668 \\
\hline Total: & & & & & 267,185 \\
\hline
\end{tabular}

Notes: The estimated number of current users in August $1975=267,185$, or 3 percent of eligible couples (using the base estimate of 8.8 million eligible couples).

${ }^{a}$ The average length of time that a loop-wearer starting Jan. 1 each year would have the loop in situ if she retained it to the time of the PFS, 1975. The data given in this column are taken from [11]

b The estimated retention rate is estimated by the "Life expectancy" method of Mauldin et al. [5], using the I.U.D. retention survey reported in [13] .

${ }^{\mathrm{c}}$ Survival rates are calculated from life tables for Pakistan (1975), given in [3], and cover elapsed times in columns 3 and 4 . 
Table 3

Number of Acceptors and Estimated Births Averted for IUD

\begin{tabular}{ccc}
\hline Calendar Year & Number of Acceptors & Births Averted $^{1}$ \\
\hline$(1)$ & $(2)$ & $(3)$ \\
\hline 1966 & 186,996 & - \\
1967 & 337,884 & 62,332 \\
1968 & 425,952 & 112,628 \\
1969 & 438,348 & 141,984 \\
1970 & 342,960 & 146,116 \\
1971 & 237,552 & 114,320 \\
1972 & 124,380 & 79,184 \\
1973 & 106,860 & 41,460 \\
1974 & 91,884 & 35,620 \\
1975 & 137,496 & 30,625 \\
\hline
\end{tabular}

${ }^{1}$ Births are assumed to be averted 18 months after acceptance and one birth is assumed to be averted for each 3 acceptors. Thus the number of births averted in $1967=1965-1966$ acceptors $\times 1 / 3$ (as stated in the weighting table)

\section{Oral Pills}

For estimating the users of this method in Table 5, the conversion assumes, besides the wastage factor, that a birth would have taken place 18 months from the time of the acceptance of the method, which puts it in the middle of the calendar year.

\section{Conventional Contraceptives}

The estimated number of the current users of conventional contraceptives, as indicated in Table 6, takes into account a wastage factor.

The total current use by our estimate is thus 16.8 percent of eligible couples using a mix of contraceptives in 1975. The method-specific use estimation is indicated below:

Estimated Current Use of Contraceptives (1975)

(Percentages)

\begin{tabular}{ccccc}
\hline $\begin{array}{c}\text { Conventional } \\
\text { Contraceptives }\end{array}$ & Oral Pills & I.U.D. & $\begin{array}{c}\text { Sterilization } \\
\text { (Male \& Female) }\end{array}$ & Total \\
\hline 9.5 & 3.2 & 3.0 & 1.1 & 16.8 \\
\hline
\end{tabular}

The above estimation of current use as compared to the PFS 1975 data is shown in Table 7, in which the ever-use figures for each contraceptives are also provided along with the percentages of the current use.

Table 4

Estimated Current Acceptors and Births Averted for Sterilization July 1965-May 1976

\begin{tabular}{ccrr}
\hline Year & $\begin{array}{c}\text { Yearly } \\
\text { Acceptors }\end{array}$ & $\begin{array}{c}\text { Births Averted } \\
\text { Col. }(2) \times 2.5\end{array}$ & $\begin{array}{c}\text { Currently } \\
\text { Protected }^{2} \\
\text { by Formula }\end{array}$ \\
\hline$(1)$ & $(2)$ & $(3)$ & $(4)$ \\
\hline $1965-66$ & 1,664 & 4,000 & 1,000 \\
$1966-67$ & 1,824 & 5,000 & 3,000 \\
$1967-68$ & 14,556 & 36,000 & 11,000 \\
$1968-69$ & 58,440 & 146,000 & 47,000 \\
$1969-70$ & 10,295 & 26,000 & 81,000 \\
$1970-71$ & 4,767 & 12,000 & 88,000 \\
$1971-72$ & 3,312 & 8,000 & 91,000 \\
$1972-73$ & 3,168 & 8,000 & 94,000 \\
$1973-74$ & 4,128 & 10,000 & 96,000 \\
$1974-75$ & 7,740 & 19,000 & 100,000 \\
\hline
\end{tabular}

Notes: Estimated number of Current Acceptors in $1975=100,000$ couples or $1.1 \%$ of eligible couples (using the base estimate of 8.8 million eligible couples).

${ }^{1}$ Births averted $=$ Yearly total $\times 2.5$

Year averted $=\quad$ Births averted are spread evenly in the 2 nd through 8 years after acceptance $(=1 / 7$ per year $)$

Current users $=\quad$ Acceptors $X .9922^{\mathrm{t}}$ (Survival rate of both spouses) for the first 8 years of acceptance.

${ }^{2}$ Assumes 7.5 years of protection for all couples with .0078 terminations per year by the death of either spouse.

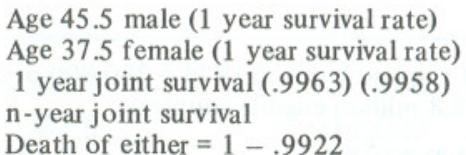

$$
\begin{aligned}
& =.9963 \\
& =.9958 \\
& =.9922 \\
& =.9922^{n} \\
& =.0078
\end{aligned}
$$

We note that there is a major discrepancy for all contraceptive methods except for sterilization. If we assume that the programme statistics are accurate, then the PFS data represent substantial under-reporting. This, however, seems unlikely from the magnitude of the factors and also from the fact that they differ by method. Why would under-reporting be much higher for one method than for another? 
As regards our own estimates, we find that the reported ever-use figures from the PFS came close to our estimates for three methods: (i) oral pills, for which the estimates are virtually equal; (ii) IUD; and (iii) sterilization, which is reported at 1.1 percent as against the 0.9 percent reported by the PFS. The problem of underreporting does not appear to be great for sterilization. The PFS questionnaire seems to have elicited a fairly close estimate of current acceptance for this method. Allowing for some under-reporting of current use, an alternative hypothesis is that there is a high over-reporting based on programme statistics or an over-estimation of notional acceptors from the units of conventional contraceptives distributed or sold. This would clearly suggest that the programme needs to re-evaluate the assumptions on which the estimation of Notional Acceptors, 'Couple Years of Protection' and 'Births Averted' are based in the programme.

Table 5

Estimated Current Users and Births Averted for Oral Pills (1965-1975)

\begin{tabular}{cccc}
\hline Year & $\begin{array}{c}\text { No. of Cycles } \\
\text { Distributed }\end{array}$ & $\begin{array}{c}\text { CYP }= \\
\text { Col. }(2) \times 3 / 4 \div 13\end{array}$ & $\begin{array}{r}\text { Birth Averted = } \\
\text { Col. (3) } \times 1 / 3^{b}\end{array}$ \\
\hline$(1)$ & $(2)$ & $(3)$ & $(4)$ \\
\hline $1965-66$ & N.A. & N.A. & N.A. \\
$1966-67$ & 44,856 & 3,000 & 1,000 \\
$1967-68$ & 20,088 & $\#$ & $\#$ \\
$1968-69$ & 5,376 & $\#$ & $\#$ \\
$1969-70$ & 4,848 & $\#$ & $\#$ \\
$1970-71$ & 4,872 & $\#$ & 1,000 \\
$1971-72$ & 59,544 & 3,000 & 3,000 \\
$1972-73$ & 162,984 & 9,000 & 24,000 \\
$1973-74$ & $1,264,656$ & 73,000 & 49,000 \\
$1974-75$ & $2,540,688$ & 147,000 & \\
\hline
\end{tabular}

Notes : Estimated number of Current Users in $1975=280,000$ or $3.2 \%$ of eligible couples (using the base estimate of 8.8 million eligible couples).

${ }^{a}$ Subtract $1 / 4$ of cycles as wastage.

${ }^{\text {b }}$ Births averted = Yearly cycles distributed $\div 39$ (= 3 years' use); $1 / 4$ of total is dropped as wastage.

N.A. = Not available

$\#=\quad$ Less than 500 units.
We note that our estimate of the current use of conventional contraceptives is almost nine times as high as that reported by the PFS, i.e. 9.5 percent as against 1.1 percent. Evidently, the figures on sales or distribution of conventional contraceptives given in the Population Planning Programme statistics do not reflect the actual use figures, even when the figures for sales and distribution are reduced by our assumed weights. The speculation that female respondents in the PFS might have seriously under-reported the use of condoms would probably not fill the gap between reported sales and reported use.

Finally, in our estimate of the births averted by the various contraceptives, we note that after adjustment the potential births averted by the Family Planning Programme range approximately from 3 percent to a maximum of 8 percent. These are still apt to be maximum estimates since the PFS suggests a lower current use of oral pills and IUDs. The PFS indicates that approximately 10 percent of the married women of reproductive age (MWRA) have reported ever-use of contraception among the PFS respondents.

Table 6

Estimated Numbers of Current Users and Births Averted for Conventional Contraceptives

\begin{tabular}{|c|c|c|c|}
\hline Year & $\begin{array}{c}\text { Million } \\
\text { Units Distributed }\end{array}$ & $\begin{array}{c}\text { C.Y.P. = } \\
\text { Col. }(2) \times 1 / 2 \\
\div 133^{a}\end{array}$ & $\begin{array}{l}\text { Births Averted = } \\
\text { Col. (3) } \times 1 / 3^{b}\end{array}$ \\
\hline (1) & (2) & (3) & (4) \\
\hline $1965-66$ & 27.1 & 104,000 & 35,000 \\
\hline $1966-67$ & 62.7 & 236,000 & 79,000 \\
\hline $1967-68$ & 96.0 & 361,000 & 120,000 \\
\hline $1968-69$ & 102.0 & 383,000 & 128,000 \\
\hline $1969-70$ & 102.0 & 383,000 & 128,000 \\
\hline $1970-71$ & 68.4 & 257,000 & 86,000 \\
\hline $1971-72$ & 25.2 & 95,000 & 32,000 \\
\hline $1972-73$ & 28.8 & 108,000 & 36,000 \\
\hline $1973-74$ & 48.0 & 180,000 & 60,000 \\
\hline $1974-75$ & 82.8 & 311,000 & 104,000 \\
\hline
\end{tabular}

Notes : Estimated number of Current Users in $1975=834.500$ or $9.5 \%$ of eligible couples (using the base estimate of 8.8 million eligible couples).

${ }^{a}$ Current Users $=$ Col. (1) $/ 133$ per year, with $1 / 2$ of total dropped as wastage. ${ }^{b}$ Births averted - (Yearly units distributed $\left./ 400\right) \times 1 / 2$ where units distributed $/ 400=3$
years' use; $1 / 4$ of total is dropped as wastage. 
Table 7

Reported Current Use and Ever-Use of Contraceptives from PFS 1975 and Estimated Current Use

(Percentages)

\begin{tabular}{ccccc}
\hline Conventional & Oral & Sterili- \\
Contraceptives & Pills & I.U.D. & $\begin{array}{l}\text { zation } \\
\text { Total }\end{array}$ \\
\hline
\end{tabular}

PFS

\section{(Ever use)}

1975 3.4 3.6

PFS

\section{(Current use)}

1975

9

6

.9

Estimated

Current use

9.5

$3.2 \quad 3.0$

1.1

Note: $\quad$ Rows 1 and 2 are computed from the PFS data; the results in Row 3 are the author's estimates based on programme statistics.

\section{IMPLICATIONS}

These results indicate that there is hardly any improvement in the reported current use, though "under-reporting" has been offered as an explanation in both survey reports [11]. The similarity in the percentages suggests that in fact not much change has taken place in the reported current use.

Furthermore, since we find that in the demographic surveys 'ever-use' figure have also not changed substantially at any stage of the programme implementation, we can assume that the 'eligible couples' have not been induced to even experiment with modern contraceptives.

It is unfortunate that the two national surveys in Pakistan (the PFS in 1968 and the PFS in 1975) do not permit a satisfactory comparative assessment of the impact of the family planning programme, for they employed different methodologies. But as they were both conducted on ever-married women of reproductive age, their result should be roughly comparable. The PFS used information obtained from female respondents only, while the earlier NIS estimated current users by combining the responses of husbands and wives. (In NIS, 50 percent of the husbands of the eligible female respondents were interviewed.) However, crudely comparable information from the NIS and the PFS on ever-use of contraceptives is shown in Table 8.
Table 8

Respondents' Reported Use of Contraceptives by NIS (1968-69) and PFS (1975) (Ever-Married Women, Ages 14 - 49)

(Percentages)

\begin{tabular}{ccc}
\hline & $\begin{array}{c}\text { NIS } \\
(1968-69)\end{array}$ & $\begin{array}{c}\text { PFS } \\
(1975)\end{array}$ \\
\hline $\begin{array}{c}\text { Reported Ever -use } \\
\text { (any method) }\end{array}$ & 9.0 & 10.8 \\
$\begin{array}{c}\text { Reported Current Use } \\
\text { (any method) }\end{array}$ & 4.4 & 4.9 \\
\hline
\end{tabular}

Source: $[9$, p. 62$]$ and $[11$, p. 93$]$.

\section{CONCLUDING REMARKS}

The extent of the programme's contribution will depend on the number of acceptors among young couples, as well as on achieving higher numbers of total acceptors with improved continuation rates. Mere acceptor statistics should not be a satisfactory measure of programme success, as was thought in the past. Emphasis should be placed on identification of acceptors along with their characteristics, such as continuous users, and dropouts should be seen as potential re-entrants for other methods. Follow-up should not be limited to dissatisfied users or problem cases but should be extended to regular users as well. All this is possible only if reliable information is being provided on all these questions.

If Family Planning Programme statistics are at all reliable, fertility rates should be falling at the present time. At least $10-16$ percent of eligible couples are reported as programme users by our assumptions, while the programme assumptions of use indicate a higher percentage of couples using contraceptives, but both procedures lead to estimates greater than the 11 percent reported in the PFS.

How much of fertility is regulated by contraception would be a useful area for future research. At present, we can at best say that the family planning programme has probably contained fertility. The family planning programme's first achievement of major importance has been in recruiting acceptors to modern methods of contraception, such as the IUD and oral pills, though the numbers of active users are quite small. The programme made modern contraceptives available on a mass scale, and people changed method or source of supply when it came into existence. In some other countries contraceptives were widely available before the establishment of a formal family planning programme, but in Pakistan that was not the case. For most couples, the programme provided the first opportunity they had to receive affective 
contraceptives on a regular basis. This means that they were given the opportunity to greatly increase their ability to avoid births.

Within the programme itself, attention must be given to ensuring that the statistics collected are accurate. Otherwise, the impact of the programme would be seriously overstated, which would hinder the acquisition of important "policy knowledge". As regards methods of contraception, it is likely that effective methods like sterilization may gain popularity among the educated urban couples. However, at the moment, sterilization is far from a favoured method even among high-parity couples. A major reason for its limited acceptance may be the restricted number of facilities providing quality service. Safe and cheap abortion continues to have a major potential for birth control, but in a society where even contraception is practised sporadically (and with culturally motivated reservations), the likelihood that practising of birth control through abortion will become widespread may be far-fetched. Thus, the Pakistan Population Programme's aim at reducing the current birth rate by 20 percent within the next five years would seem to be over ambitious. If the programme has become heavily dependent on conventional contraceptives, which seems to be the case from service statistics, then better data on actual use are needed in order to measure the impact on fertility. Knowing that a family planning programme is only one of the major policy instruments designed to affect fertility, we should be able to judge its significance in terms of other relevant socio-economic and demographic factors.

\section{REFERENCES}

1. Bean, Lee, and W. Seltzer. "Couple-Years of Protection and Births Averted: A Methodological Examination”. Demography. Vol. 5, No. 2. 1968. pp. 947-959.

2. Cuca, Roberto, and Lee L. Bean. Family Planning in Pakistan: A Review of the Continuous Motivation System. Washington, D. C. : IBRD (Human Resources Division, Economic Development Institute). February 1975. Mimeographed.

3. Farooqui, Naseem Iqbal, and Iqbal Alam. "Provisional Abridged Life Tables for Urban and Rural Areas in Pakistan based on PGS 1968 and 1971". Pakistan Development Review. Vol. XIII, No. 3. Autumn 1974.

4. Hardee, J. Gilbert, and Adalino P. Satterthwaite. Country Profiles: PAKISTAN. New York: The Population Council and The International Institute for the Study of Human Reproduction, Columbia University. March 1970.

5. Mauldin, W. Parker, Dorothy Nortman, and Frederick F. Stephan. Studies in Family Planning, No. 18 (and Supplement) - RETENTION OF IUDs : An International Comparison. New York: The Population Council. April 1967.
6. Osborne, Richard W. "The Sialkot Experience". Studies in Family Planning. Vol. V, No. 4. August 1974.

7. Pakistan. Planning Commission. Annual Plan 1976- 77. Islamabad. 1976.

8. Pakistan. Planning Commission. Third Five Year Plan, 1965-70. Karachi. 1965.

9. Pakistan. Population Planning Council. National Impact Survey Report. Lahore: Training, Research and Evaluation Centre (TREC). n.d.

10. Pakistan. Population Planning Division. Population Planning Programme: A Profile. Islamabad. June 1976.

11. Population Planning Council of Pakistan. World Fertility Survey: PAKISTAN FERTILITY SURVEY, First Report. Islamabad. October 1976.

12. Shafiullah, A. B. M. Demographic Effectiveness of the Vasectomy Programme in East Pakistan. Dacca: Directorate of Family Planning 1970.

13. Siddiqui, Habib R., and Donald W. Helbig. "Consistency of Response and Significance of Non-Response, 1967 IUD Retention Survey in West Pakistan". Proceedings: Fifth Biannual SEMINAR on Research in Family Planning, Lahore, November 7-9, 1968. Karachi: National Research Institute of Family Planning. n. d. 